\title{
Expressão do mRNA de genes mitocondriais e desempenho produtivo de codornas alimentadas com glicerol
}

\author{
Stefânia Caroline Claudino da Silva(1), Eliane Gasparino(1), Débora Marques Voltolini( ${ }^{(1)}$, \\ Simara Marcia Marcato(1) e Fernanda Tanamati( ${ }^{(1)}$
} (1)Universidade Estadual de Maringá, Avenida Colombo, no 5.790, CEP 87020-900 Maringá, PR. E-mail: stefania_caroline@hotmail.com,
egasparino@hotmail.com, deborasommer@yahoo.com.br, simaramm@yahoo.com.br, fertanamati@gmail.com

Resumo - O objetivo deste trabalho foi avaliar o efeito de dietas com glicerol no desempenho produtivo de codornas japonesas de corte e na expressão do mRNA de genes mitocondriais da proteína adenina nucleotídeo translocase (ANT) e da proteína desacopladora (UCP), envolvidas no metabolismo energético e na resposta ao estresse oxidativo. As codornas foram alimentadas com dietas contendo 0,8 e $12 \%$ de glicerol, em substituição parcial ao milho. Aos 28 dias de idade, o RNA total foi extraído de amostras do músculo do peito e a síntese do cDNA foi feita por meio de qRT-PCR com iniciadores específicos para genes da ANT e UCP, obtidos de Gallus gallus. A conversão alimentar e o consumo de ração foram avaliados para as três dietas testadas. A adição de $8 \%$ de glicerol não afetou o desempenho dos animais. No entanto, a adição de $12 \%$ aumentou o consumo de ração e piorou a conversão alimentar. O ganho de peso não foi afetado pela inclusão de glicerol na dieta. No grupo alimentado com $8 \%$ de glicerol, a expressão da UCP aumentou, mas a da ANT não variou, em comparação ao controle. A expressão da UCP foi menor e a da ANT foi maior no grupo alimentado com $12 \%$ de glicerol. A inclusão de $8 \%$ de glicerol na dieta não afeta o desempenho de codornas de corte, embora aumente a expressão da UCP. A inclusão de 12\% de glicerol piora o desempenho e aumenta a expressão da ANT.

Termos para indexação: Coturnix coturnix, estresse oxidativo, fosforilação oxidativa, metabolismo energético.

\section{mRNA expression of mitochondrial genes and productive performance of quails fed with glycerol}

\begin{abstract}
The objective of this work was to evaluate the effect of diets containing glycerol on the productive performance of Japanese meat quails and on the mRNA expression of the mitochondrial genes of the adenine nucleotide translocase (ANT) and uncoupling protein (UCP), involved in energy metabolism and oxidative stress response. The quail were fed diets containing 0,8 , and $12 \%$ glycerol in partial substitution of corn. At 28 days of age, total RNA was extracted from samples of breast muscle and cDNA synthesis was done with qRT-PCR using specific primers for ANT and UCP genes, obtained from Gallus gallus. Feed conversion and feed intake were evaluated for the three tested diets. The addition of $8 \%$ glycerol did not affect performance. However, the addition of $12 \%$ glycerol increased feed intake and worsen feed conversion. Animal weight gain was not affected by glycerol inclusion in the diet. In the group fed with $8 \%$ glycerol, UCP expression increased, but that of ANT did not vary in comparison to the control. The expression of UCP was lower and that of ANT was higher in the group fed with $12 \%$ glycerol. The inclusion of $8 \%$ glycerol in the diet does not affect the performance of meat quails, although it increases the expression of UCP. The inclusion of $12 \%$ glycerol decreases performance and increases the expression of ANT.
\end{abstract}

Index terms: Coturnix coturnix, oxidative stress, oxidative phosphorylation, energy metabolism.

\section{Introdução}

A utilização de subprodutos na dieta de animais de interesse zootécnico pode diminuir o custo de produção e, consequentemente, aumentar a rentabilidade da atividade. Quando financeiramente rentável, o glicerol, um subproduto da indústria do biodiesel, pode ser usado como substituto parcial do milho para alimentação animal (Cerrate et al., 2006), por apresentar valor energético semelhante $\left(3.434 \mathrm{kcal} \mathrm{kg}^{-1}\right)$ (Dozier et al., 2008). Absorvido de forma passiva (Guyton, 1991), o glicerol tem sabor adocicado e pequeno peso molecular (Rivaldi et al., 2008), o que influencia o consumo de ração (Pasquetti, 2011).

Em frangos de corte, a relação entre função mitocondrial e eficiência alimentar tem sido relatada (Parker et al., 2008). Durante a fosforilação oxidativa, podem haver falhas na condução de prótons do 
espaço intermembranoso para a matriz mitocondrial (Brand et al., 1995), em razão do desacoplamento no transporte de prótons causado por proteínas específicas que funcionam como desacopladores de membrana, o que pode resultar em ineficiência mitocondrial (Rolfe \& Brand, 1996, 1997).

Em codornas e frangos de corte, a inclusão de glicerol na dieta pode afetar características de desempenho, como ganho de peso e conversão alimentar (Raber et al., 2009; Batista, 2010), além de reduzir ou aumentar a expressão do RNA mensageiro (mRNA) de alguns genes mitocondriais, como a adenina nucleotídeo translocase (ANT) e a proteína desacopladora (UCP), relacionadas à síntese de ATP e ao estresse oxidativo (Gasparino et al., 2012).

Apesar de mostrarem a relação entre a conversão alimentar e a cadeia transportadora de elétrons (Bottje \& Carstens, 2009), a maioria dos estudos neste tema busca resultados de expressão de genes baseados na genética dos indivíduos e não em dietas diferenciadas. Dessa forma, há pouco conhecimento a respeito do possível efeito de diferentes nutrientes ou de seus níveis na ração sobre a expressão de genes mitocondriais. As informações existentes sobre o efeito de níveis nutricionais na fosforilação oxidativa mostram que rações com maior inclusão de proteína bruta ou de ácidos graxos de cadeia longa reduziram a síntese de ATP ou a relação ADP: $\mathrm{O}_{2}$ (Clandinin, 1978). Renner et al. (1979) encontraram menor eficiência energética em frangos alimentados com alta inclusão de óleo de colza, e atribuíram esse resultado ao desacoplamento da fosforilação oxidativa.

Portanto, são necessários estudos sobre o efeito dos nutrientes tanto na expressão de genes relacionados à cadeia transportadora de elétrons quanto na fosforilação oxidativa.

O objetivo deste trabalho foi avaliar o efeito de dietas contendo glicerol no desempenho produtivo de codornas japonesas de corte e na expressão de genes mitocondriais das proteínas ANT e UCP, envolvidas no metabolismo energético e na resposta ao estresse oxidativo.

\section{Material e Métodos}

O experimento foi conduzido no setor de avicultura e no Laboratório de Genética Molecular, do Departamento de Zootecnia, da Universidade Estadual de Maringá (UEM), PR. Foram utilizadas 450 codornas japonesas (Coturnix coturnix japonica) de corte, de um dia de idade, distribuídas em delineamento inteiramente casualizado, com três tratamentos (sem glicerol e com a inclusão de 8 e $12 \%$ de glicerol na ração), o que totalizou 150 codornas por tratamento, que foram divididas em cinco repetições, com 30 codornas por box. O box foi considerado a unidade experimental. Os animais foram alojados em galpão convencional, em boxes de 2,5 $\mathrm{m}^{2}$, os quais foram forrados por cama de casca de arroz. Utilizou-se o programa de iluminação contínua, durante todo o período experimental.

Foram avaliadas três dietas experimentais: uma ração controle (sem glicerol), e duas com a inclusão de 8 e $12 \%$ de glicerol, formuladas à base de milho e farelo de soja, conforme recomendações nutricionais de National Research Council (1994) e Rostagno (2005), exceto no que se refere à inclusão de glicerol (Tabela 1).

Tabela 1. Participação dos ingredientes na composição centesimal (\%) das dietas com inclusão de 0,8 e 12\% de glicerina bruta.

\begin{tabular}{|c|c|c|c|}
\hline \multirow[t]{2}{*}{ Ingredientes } & \multicolumn{3}{|c|}{ Glicerina bruta } \\
\hline & $0 \%$ & $8 \%$ & $12 \%$ \\
\hline Milho grão & 54,58 & 46,48 & 42,44 \\
\hline Farelo de soja $45 \%$ & 37,84 & 39,37 & 40,13 \\
\hline Glicerina bruta & 0,00 & 8,00 & 12,00 \\
\hline Óleo de soja & 2,88 & 1,44 & 0,73 \\
\hline Fosfato bicálcico & 1,61 & 1,63 & 1,64 \\
\hline L-Lisina HCL & 0,65 & 0,84 & 0,82 \\
\hline DL-Metionina & 0,66 & 0,66 & 0,67 \\
\hline L-Treonina & 0,44 & 0,43 & 0,43 \\
\hline Sal comum & 0,40 & 0,40 & 0,40 \\
\hline Suplemento vitamínico ${ }^{(1)}$ & 0,40 & 0,40 & 0,40 \\
\hline Calcário & 0,28 & 0,26 & 0,26 \\
\hline Suplemento mineral $^{(1)}$ & 0,07 & 0,07 & 0,07 \\
\hline Antioxidante $^{(2)}$ & 0,01 & 0,01 & 0,01 \\
\hline \multicolumn{4}{|l|}{ Composição nutricional } \\
\hline Proteína bruta & 23,20 & 23,20 & 23,20 \\
\hline Cálcio & 0,61 & 0,61 & 0,61 \\
\hline Fósforo disponível & 0,41 & 0,41 & 0,41 \\
\hline Energia metabolizável $\left(\mathrm{kcal} \mathrm{kg}^{-1}\right)$ & 3.000 & 3.000 & 3.000 \\
\hline Metionina + cistina digestível & 1,33 & 1,33 & 1,33 \\
\hline Lisina digestível & 1,88 & 1,88 & 1,88 \\
\hline Treonina digestível & 1,14 & 1,14 & 1,14 \\
\hline Triptofano digestível & 0,28 & 0,28 & 0,28 \\
\hline Sódio & 0,18 & 0,31 & 0,37 \\
\hline
\end{tabular}

${ }^{(1)}$ Suplementação vitamínica/mineral (níveis de garantia por kg do produto): vitamina A, 4.500.000 UI; vitamina D3, $1.250 .000 \mathrm{UI}$; vitamina E, $4.000 \mathrm{mg}$; vitamina B1, $278 \mathrm{mg}$; vitamina B2, $2.000 \mathrm{mg}$; vitamina B6, $525 \mathrm{mg}$; vitamina B12, $5.000 \mathrm{mcg}$; vitamina $\mathrm{K} 3,1.007 \mathrm{mg}$; pantotenato de cálcio, $4.000 \mathrm{mg}$; niacina, $10.000 \mathrm{mg}$; colina, $140.000 \mathrm{mg}$; antioxidante, $5.000 \mathrm{mg}$; zinco, $31.500 \mathrm{mg}$; ferro, $24.500 \mathrm{mg}$; manganês, $38.750 \mathrm{mg}$; cobre, $7.656 \mathrm{mg}$; cobalto, $100 \mathrm{mg}$; iodo, $484 \mathrm{mg}$; selênio, $127 \mathrm{mg} .{ }^{(2)} \mathrm{BHT}$, butil-hidroxi-tolueno. 
As codornas foram pesadas no primeiro dia e aos 28 dias de vida, para determinação do ganho de peso corporal, e o consumo de ração foi controlado diariamente para cálculo da conversão alimentar. Dez codornas de cada tratamento foram abatidas por deslocamento cervical, aos 28 dias de idade, tendo-se amostrado o músculo peitoral (Pectoralis superficialis) de cada ave. As amostras foram acondicionadas em "RNA holder" (BioAgency Biotecnologia Ltda., São Paulo, SP) e armazenadas a $-20^{\circ} \mathrm{C}$ até o momento da extração do RNA.

O RNA total foi extraído com uso do reagente Trizol (Invitrogen, Carlsbad, CA, EUA), na proporção de $1 \mathrm{~mL}$ para cada $100 \mathrm{mg}$ de tecido, de acordo com instruções do fabricante. A concentração do RNA total foi avaliada por meio de espectrofotômetro em comprimento de onda de 260 e $280 \mathrm{~nm}$, e sua integridade foi avaliada em gel de agarose 1,2\%; o RNA foi visualizado em luz ultravioleta (Bitencourt et al., 2011). Na síntese do cDNA, foi utilizado o kit SuperScript III First-Strand Synthesis SuperMix (Invitrogen Corporation, São Paulo, SP) para a reação de PCR via transcriptase reversa quantitativa (qRT-PCR). Foram adicionados $6 \mu \mathrm{L}$ de RNA total, $1 \mu \mathrm{L}$ de oligo (dT), $50 \mu \mathrm{mol} \mathrm{L}^{-1}$ de oligo (dT) $)_{20}$ e $1 \mu \mathrm{L}$ de tampão de anelamento ("annealing buffer"). A reação foi incubada por $5 \mathrm{~min}$, a $65^{\circ} \mathrm{C}$, e colocada em gelo por $1 \mathrm{~min}$. Posteriormente, foram adicionados $10 \mu \mathrm{L}$ de solução 2x First-Strand Reaction Mix (Invitrogen Corporation, São Paulo, SP) e $2 \mu \mathrm{L}$ de solução contendo a enzima transcriptase reversa SuperScript III e o inibidor de RNAse. A solução foi incubada por $50 \mathrm{~min}$, a $50^{\circ} \mathrm{C}$. A reação foi incubada novamente por $5 \mathrm{~min}$, a $85^{\circ} \mathrm{C}$, e imediatamente colocada em gelo. As amostras foram armazenadas a $-20^{\circ} \mathrm{C}$ até o momento das análises. Para as reações de qRT-PCR, em tempo real, foi utilizado o composto fluorescente, SYBR Green PCR Master Mix, (Applied Biosystems do Brasil, São Paulo, SP), de acordo com a recomendação do fabricante. Foram utilizados iniciadores específicos dos genes da ANT e da UCP obtidos de Gallus gallus por Ojano-Dirain et al. (2007):

UCP "forward" - GCAGCGGCAGATGAGCTT e UCP"reverse"-AGAGCTGCTTCACAGAGTCGTAGA; ANT "forward" - TGTGGCTGGTGTGGTTTCCTA e ANT "reverse" - GCGTCCTGACTGCATCATCA. $O$ gene da $\beta$-actina foi utilizado como controle endógeno da reação. Todas as análises foram realizadas em volume final de $25 \mu \mathrm{L}$ e em duplicatas.

Os dados foram analisados por meio do procedimento GLM do SAS. O procedimento Univariate foi utilizado para verificar a normalidade dos resíduos da expressão dos genes em estudo (expressos com $2^{-\Delta \mathrm{Ct}}$ ) e dos dados de produção. Procedeu-se à análise de variância, e as médias foram comparadas pelo teste de Tukey, a $5 \%$ de probabilidade.

\section{Resultados e Discussão}

Os tratamentos não tiveram efeito significativo sobre o ganho de peso das codornas $(181,70 \pm 7,64 \mathrm{~g})$; porém, houve efeito significativo para consumo de ração e conversão alimentar (Figura 1). O consumo de ração foi significativamente maior com a inclusão
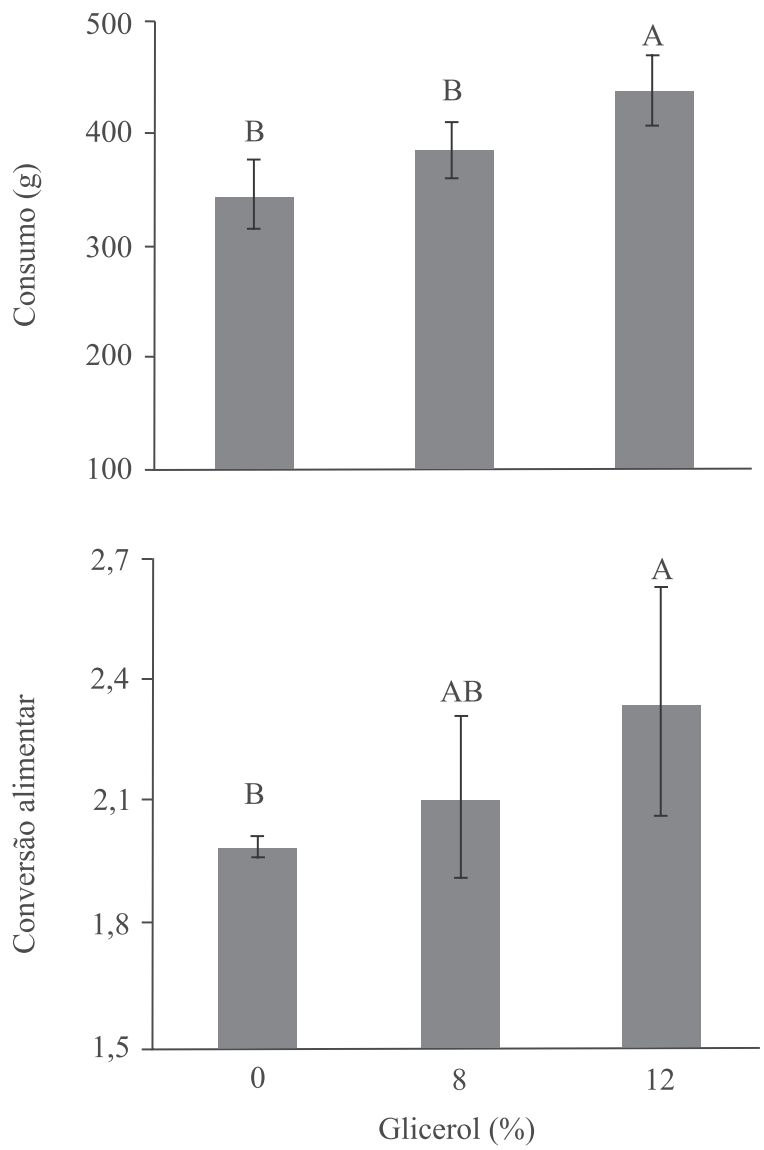

Figura 1. Consumo total e conversão alimentar de codornas alimentadas com rações contendo 0, 8 e 12\% de glicerol, aos 28 dias de idade. Médias seguidas de letras iguais não diferem pelo teste de Tukey, a 5\% de probabilidade. 
de $12 \%$ de glicerol na dieta, mas não diferiu entre os tratamentos controle e com inclusão de $8 \%$ de glicerol. O maior consumo de ração pode ter ocorrido pela maior palatabilidade da dieta com glicerol, em razão de seu sabor adocicado (Pasquetti, 2011). A inclusão de $12 \%$ de glicerol resultou em pior conversão alimentar, com valores $14,59 \%$ maiores, em média, do que os observados nos demais tratamentos, na fase de 1 a 28 dias de idade.

De acordo com a literatura, o valor máximo recomendado de inclusão de glicerol em dietas de codornas de corte, dos 15 aos 35 dias de idade, é de 15\% (Pasquetti, 2011). Entretanto, a inclusão de 12\% de glicerol, no presente trabalho, parece já ter excedido a capacidade metabólica dos animais (Min et al., 2010), o que indica a necessidade de novos estudos para determinar a inclusão máxima de glicerol nessa faixa de idade.

A inclusão de glicerol nas dietas influenciou a expressão de ANT e UCP (Figura 2). Quando se adicionou $8 \%$ de glicerol, não se observou diferença na expressão de mRNA da ANT, em comparação ao grupo controle (sem glicerol), mas houve aumento da expressão da ANT com a inclusão de $12 \%$ de glicerol.

A ANT tem, como papel principal, a troca de ATP e ADP (Ojano-Dirain et al., 2007). Em situações em que a função de troca ADP-ATP é prejudicada, a ANT desempenha importante papel na redução de espécies reativas de oxigênio (ROS) (Iqbal et al., 2005) e na indução de apoptose (Won et al., 2010). Desse modo, este aumento de expressão da ANT com a inclusão de $12 \%$ de glicerol na dieta pode ser visto como uma resposta induzida pelas ROS, uma vez que a ANT é conhecida por sua capacidade de desacoplamento (Boudina \& Abel, 2006), que poderia reduzir a produção de ROS mitocondriais (Echtay et al., 2002).

A pior conversão alimentar dos animais alimentados com $12 \%$ de glicerol, associada à maior expressão da ANT, é forte indício da ação prejudicial desse nível de inclusão sobre a atividade de troca ATP-ADP que, quando deficiente, torna os animais menos eficientes em produzir energia. Estes resultados estão de acordo com os de Tinsley et al. (2010) e Iqbal et al. (2004), que encontraram maior expressão da ANT em animais com baixa eficiência alimentar.

A suplementação de $12 \%$ de glicerol promoveu redução de 35 e 53\% na expressão do mRNA da UCP, em comparação aos tratamentos sem glicerol e com
$8 \%$, respectivamente (Figura 2). A inclusão de $8 \%$ de glicerol promoveu aumento na expressão da UCP.

Esperava-se aumento da expressão da UCP nas dietas com $12 \%$ de glicerol, uma vez que a UCP tem a ação benéfica de reduzir a produção de radicais livres (Miwa et al., 2003). A maior expressão da UCP na dieta com $8 \%$ de glicerol, em comparação àquela com $12 \%$, pode ter ocorrido em razão da maior quantidade de ácidos graxos de cadeia longa (Abe et al., 2006) proveniente do óleo de soja, que esteve presente em concentrações mais altas nesta dieta, o que corrobora os resultados de Gasparino et al. (2012).

Os resultados obtidos no presente trabalho evidenciam que, embora as rações sejam isoenergéticas, a fonte de energia utilizada influencia a expressão gênica da UCP e da ANT, que estão relacionadas ao metabolismo energético celular. Além disso, a inclusão
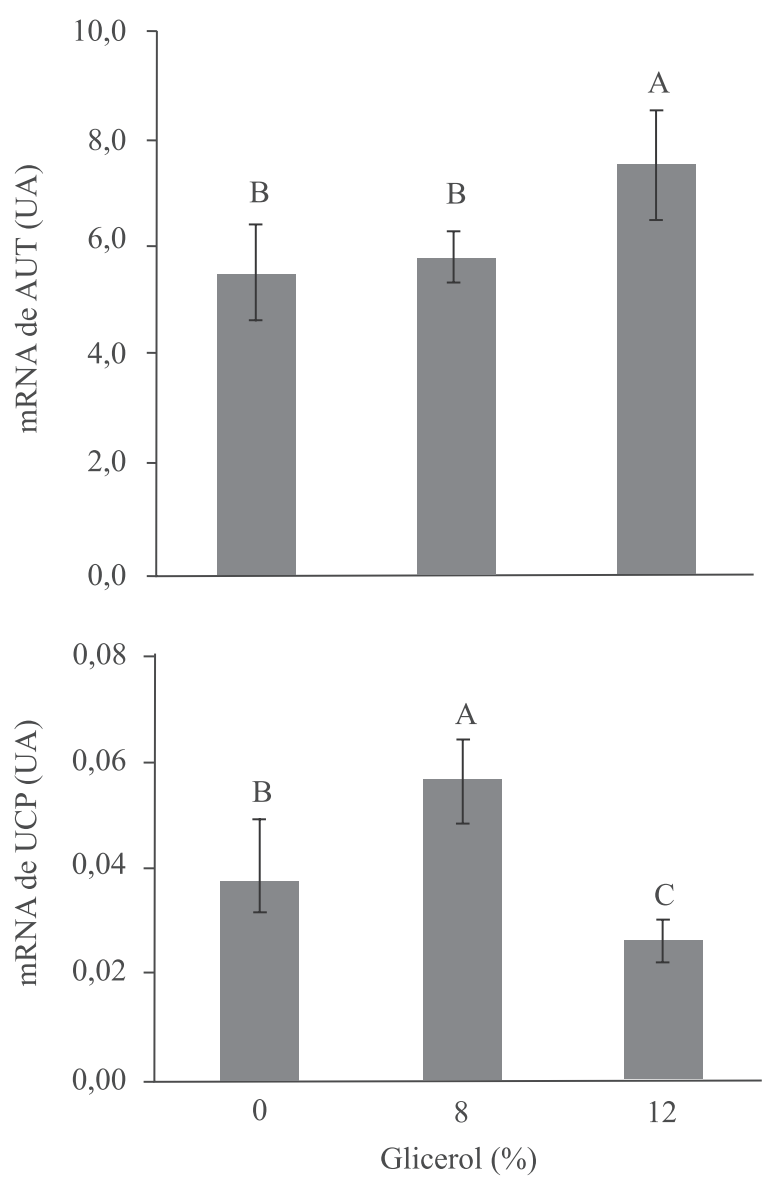

Figura 2. Expressão do RNA mensageiro (mRNA) da adenina nucleotídeo translocase (ANT) e da proteína desacopladora (UCP). Médias seguidas de letras iguais não diferem pelo teste de Tukey, a 5\% de probabilidade. 
de diferentes concentrações de glicerol na dieta de codornas, na fase de 1 a 28 dias de idade, altera o desempenho produtivo desses animais.

\section{Conclusões}

1. A inclusão de $8 \%$ de glicerol na dieta não afeta a expressão da adenina nucleotídeo translocase (ANT), o ganho de peso, a conversão alimentar e o consumo de ração de codornas de corte, mas aumenta a expressão da proteína desacopladora (UCP).

2. A dieta com $12 \%$ de glicerol é prejudicial ao desempenho produtivo de codornas de corte com até 28 dias de idade, pois aumenta o consumo de ração e piora a conversão alimentar.

3. A adição de $12 \%$ de glicerol reduz a expressão do mRNA da UCP e aumenta a expressão do mRNA da ANT, proteínas relacionadas ao estresse oxidativo.

\section{Referências}

ABE, T.; MUJAHID, A.; SATO, K.; AKIBA, Y.; TOYOMIZU, M. Possible role of avian uncoupling protein in down-regulating mitochondrial superoxide production in skeletal muscle of fasted chickens. FEBS Letters, v.580, p.4815-4822, 2006. DOI: 10.1016/j.febslet.2006.07.070.

BATISTA, E. Avaliação nutricional do glicerol para codornas de corte. 2010. 69p. Dissertação (Mestrado) - Universidade Estadual de Maringá, Maringá.

BITENCOURT, G.A.; CHIARI, L.; VALLE, C.B.; LAURA, V.A.; MORO, J.R. Avaliação de diferentes métodos para extração de RNA total de folhas e raízes de braquiária. Campo Grande: Embrapa Gado de Corte, 2011. 22p. (Embrapa Gado de Corte. Boletim de pesquisa e desenvolvimento, 29).

BOtTJE, W.G.; CARSTENS, G. Association of mitochondrial function and feed efficiency in poultry and livestock species. Journal of Animal Science, v.87, p.48-63, 2009. DOI: 10.2527/ jas.2008-1379.

BOUDINA, S.; ABEL, E.D. Mitochondrial uncoupling: a key contributor to reduced cardiac efficiency in diabetes. Physiology, v.21, p.250-258, 2006. DOI: 10.1152/physiol.00008.2006.

BRAND, M.D.; CHIEN, L.F.; AINSCOW, E.K.; ROLFE, D.F.S.; PORTER, R.K. The causes and functions of mitochondrial proton leak. Biochimica et Biophysica Acta, v.1187, p.132-139, 1995.

CERRATE, S.; YAN, F.; WANG, Z.; COTO, C.; SACAKLI, P.; WALDROUP, P.W. Evaluation of glycerine from biodiesel production as a feed ingredient for broilers. International Journal of Poultry Science, v.11, p.1001-1007, 2006.

CLANDININ, M.T. The role of dietary long chain fatty acids in mitochondrial structure and function. Effects on rat cardiac mitochondrial respiration. Journal of Nutrition, v.108, p.273-281, 1978.
DOZIER III, W.A.; KERR, B.J.; CORZO, A.; KIDD, M.T.; WEBER, T.E.; BREGENDAHL, K. Apparent metabolizable energy of glycerin for broiler chickens. Poultry Science, v.87, p.317-322, 2008. DOI: 10.3382/ps.2007-00309.

ECHTAY, K.S.; ROUSSEL, D.; ST-PIERRE, J.; JEKABSONS, M.B.; CADENAS, S.; STUART, J.A.; HARPER, J.A.; ROEBUCK, S.J.; MORRISON, A.; PICKERING, S.; CLAPHAM, J.C.; BRAND, M.D. Superoxide activates mitochondrial uncoupling proteins. Nature, v.415, p.96-99, 2002. DOI: 10.1038/415096a.

GASPARINO, E.; GUIMARÃES, S.E.F.; MARTINS, E.M.; OLIVEIRA NETO, A.; VESCO, A.P.D. Effect of glycerol on mRNA expression of growth hormone, insulin-like growth factor, and mitochondrial breast muscle genes of Japanese quails. British Poultry Science, v.53, p.497-507, 2012. DOI: 10.1080/00071668.2012.716507.

GIANFELICI, M.F. Uso de glicerol como fonte de energia para frangos de corte. 2009. 129p. Dissertação (Mestrado) Universidade Federal do Rio Grande do Sul, Porto Alegre.

GUYTON, A.C. Textbook of medical physiology. Philadelphia: Saunders Company, 1991.

IQBAL, M.; PUMFORD, N.R.; TANG, Z.X.; LASSITER, K.; OJANO-DIRAIN, C.; WING, T.; COOPER, M.; BOTTJE, W. Compromised liver mitochondrial function and complex activity in low feed efficient broilers are associated with higher oxidative stress and differential protein expression. Poultry Science, v.84, p.933-941, 2005.

IQBAL, M.; PUMFORD, N.R.; TANG, Z.X.; LASSITER, K.; WING, T.; COOPER, M.; BOTTJE, W. Low feed efficient broilers within a single genetic line exhibit higher oxidative stress and protein expression in breast muscle with lower mitochondrial complex activity. Poultry Science, v.83, p.474-484, 2004.

MIN, Y.N.; YAN, F; LIU, F.Z.; COTO, C.; WALDROUP, P.W. Glycerin-A new energy source for poultry. International Journal of Poultry Science, v.9, p.1-4, 2010. DOI: 10.3923/ijps.2010.1.4.

MIWA, S.; ST-PIERRE, J.; PARTRIDGE, L.; BRAND, M.D. Superoxide and hydrogen peroxide production in Drosophila mitochondria. Free Radical Biology and Medicine, v.35, p.938-948, 2003. DOI: 10.1016/S0891-5849(03)00464-7.

NATIONAL RESEARCH COUNCIL. Nutrient requirement of poultry. $9^{\text {th }}$ ed. Washington: NRC, 1994.

OJANO-DIRAIN, C.; TOYOMIZU, M.; WING, T.; COOPER, M.; BOTTJE, W.G. Gene expression in breast muscle and duodenum from low and high feed efficient broilers. Poultry Science, v.86, p.372-381, 2007.

PARKER, N.; AFFOURTIT, C.; VIDAL-PUIG, A.; BRAND, M.D. Energization-dependent endogenous activation of proton conductance in skeletal muscle mitochondria. The Biochemical Journal, v.41, p.131-139, 2008. DOI: 10.1042/BJ20080006.

PASQUETTI, J.T. Avaliação nutricional da glicerina bruta ou semipurificada, oriundas de gordura animal e óleo vegetal, para codornas de corte. 2011. 110p. Dissertação (Mestrado) Universidade Estadual de Maringá, Maringá.

RABER, M.R.; RIBEIRO, A.M.L.; KESSLER, A. de M.; ARNAIZ, V. Suplementação de glicerol ou de lecitina em diferentes níveis 
de ácidos graxos livres em dietas para frangos de corte. Ciência Animal Brasileira, v.10, p.745-753, 2009.

RENNER, R.; INNIS, S.N.; CLANDININ, M.T. Effects of high and low erucic acid rapeseed oils on energy metabolism and mitochondrial function of the chick. Journal of Nutrition, v.109, p.378-387, 1979.

RIVALDI, J.D.; SARROUB, B.F.; FIORILO, SILVA, S.S. Glicerol de biodiesel. Biotecnologia, Ciência e Desenvolvimento, v.37, p.44-51, 2008.

ROLFE, D.F.S.; BRAND, M.D. Contribution of mitochondrial proton leak to skeletal muscle respiration and to standard metabolic rate. American Journal of Physiology, v.271, p.1380-1389, 1996.

ROLFE, D.F.S.; BRAND, M.D. The physiological significance of mitochondrial proton leak in animal cells and tissues. Bioscience Reports, v.17, p.9-16, 1997. DOI: 10.1023/A:1027327015957.
ROSTAGNO, H.S. (Ed.). Brazilian tables for poultry and swine: composition of feedstuffs and nutritional requirements. $2^{\text {nd }}$ ed. Viçosa: UFV, 2005. 181p.

TINSLEY, N.; IQBAL, M.; PUMFORD, N.R.; LASSITER, K.; OJANO-DIRAIN, C.; WING, T.; BOTTJE, W. Investigation of mitochondrial protein expression and oxidation in heart muscle in low and high feed efficient male broilers in a single genetic line. Poultry Science, v.89, p.349-352, 2010. DOI: 10.3382/ ps.2009-00138.

WON, J.C.; PARK, J.Y.; KIM, Y.M.; KOH, E.H.; SEOL, S.; JEON, B.H.; HAN, J.; KIM, J.R.; PARK, T.S.; CHOI, C.S.; LEE, W.J.; KIM, M.S.; LEE, I.K.; YOUN, J.H.; LEE, K.U. Peroxisome proliferator-activated receptor-gamma coactivator 1-alpha overexpression prevents endothelial apoptosis by increasing ATP/ADP translocase activity. Arteriosclerosis, Thrombosis, and Vascular Biology, v.30, p.290-297, 2010. DOI: 10.1161/ ATVBAHA.109.198721.

Recebido em 17 de julho de 2012 e aprovado em 30 de janeiro de 2013 